\section{(6) OPEN ACCESS}

\title{
Neglected exposure route: cobalt on skin and its associations with urinary cobalt levels
}

\author{
Jolinde Kettelarij, ${ }_{1}^{1}$ Klara Midander, ${ }^{1}$ Carola Lidén, ${ }^{1}$ Matteo Bottai, ${ }^{2}$ Anneli Julander ${ }^{1}$
}

\begin{abstract}
- Additional material is published online only. To view please visit the journal online (http://dx.doi.org/10.1136/ oemed-2018-105099).

${ }^{1}$ Unit of Work Environment Toxicology, Institute of Environmental Medicine, Karolinska Institutet, Stockholm, Sweden

2Unit of Biostatistics, Institute of Environmental Medicine, Karolinska Institutet, Stockholm, Sweden
\end{abstract}

\section{Correspondence to}

Dr Anneli Julander, Unit of Work Environment Toxicology, Institute of Environmental Medicine, Karolinska Institutet, Stockholm 171 77, Sweden; anneli.julander@ki.se

Received 26 February 2018 Revised 7 June 2018

Accepted 4 August 2018 Published Online First

9 January 2018
ABSTRACT
Objectives

Objectives Cobalt (Co) exposure is associated with adverse health effects including skin sensitisation, asthma and interstitial lung fibrosis. Exposure to $C_{0}$ in industrial settings is often assessed using air samples or biomonitoring in urine. Skin exposure is rarely measured. Aim of this study was to quantify and compare the importance of Co skin exposure and respiratory exposure in determining urinary Co concentrations.

Methods Co skin exposure was measured in 76 hard metal workers by acid wipe sampling before and at the end of work shifts. Spot urine was collected during a 24-hour period from the start of a shift. Respiratory exposure was measured by personal inhalable dust sampling during a shift in 30 workers. Co was analysed by inductively coupled plasma mass spectrometry. Results Quantile regression modelling showed that a doubling of Co on skin before or at the end of shift increased the median urinary concentration of $\mathrm{Co}$ by $70 \%(p<0.001)$ or $32 \%(p<0.001)$, respectively. A doubling of $\mathrm{Co}$ in air increased median urinary Co by 38\% ( $p<0.001)$. Co skin exposures were still significantly associated with urinary Co after excluding a group of workers with high respiratory exposure (33\%, $p=0.021$ and $17 \%, p=0.002$ ).

Conclusions The results indicate an association between Co skin exposure and urinary Co concentrations. This should be considered when using urinary $\mathrm{Co}$ as a biomarker of exposure.

\section{INTRODUCTION}

Cobalt (Co) exposure is associated with adverse health effects including skin sensitisation, asthma, interstitial lung fibrosis and cancer. ${ }^{1-3}$

Exposure to Co has been reported for hard metal workers, gas turbine and space propulsion workers, base metal refinery workers, dental technicians, construction workers and workers in the electronics industry. ${ }^{4-15}$ Several exposure studies in occupational settings investigate respiratory exposure, because of the toxicity of Co to the lungs. However, few occupational studies have quantified Co skin exposure in workers. ${ }^{6101415}$ Sources of Co skin exposure within the hard metal industry have recently been identified and included the deposition of particles and dust, handling of hard metal items during production as well as touching production equipment and other work materials. ${ }^{16}$

Urinary Co is frequently used as an exposure biomarker in occupational settings, ${ }^{5} 615$ 17-19 due to urine being the primary elimination route of Co after respiratory exposure in humans. ${ }^{20}$ Several

\section{Key messages}

What is already known about this subject?

- Due to the adverse health effects of cobalt (Co), urinary Co as biomarker of Co respiratory exposure is frequently used in occupational settings. The association between skin exposure and urinary excretion of $\mathrm{Co}$ is unclear.

\section{What are the new findings?}

- Urinary Co was demonstrated to be a suitable biomarker for respiratory and skin exposure for a wide exposure range. Skin exposure was shown to be an additional determinant of urinary Co levels.

\section{How might this impact on policy or clinical practice in the foreseeable future? \\ - Skin exposure to Co should not be neglected when using $\mathrm{Co}$ in urine as biomarker of exposure.}

studies have found an association between respiratory exposure and urinary Co in occupationally exposed workers. ${ }^{6} 192122$ Little is known about the association between skin exposure and urinary excretion of Co, as it has only been studied in a few healthy volunteers. ${ }^{56}$ However, in vitro experiments have shown that metallic Co in particle form can be ionised in synthetic sweat and that Co ions pass through human skin. ${ }^{23} 24$

There is a lack of studies measuring both respiratory and skin exposure to Co and simultaneously monitoring Co urinary levels, which was the motivation for our study. Our objective was to quantify and compare the importance of skin exposure and air exposure in determining urinary Co concentrations. To achieve this objective, study participants from a hard metal company provided data over a wide range of skin and respiratory exposure levels.

\section{MATERIALS AND METHODS \\ Study design}

The study was performed at a hard metal company in Sweden, where both Co powder (micron sized), used as binding agent (concentration 6\%-30\%) for tungsten carbide to form hard metal alloys (cemented tungsten carbides), and sintered material were handled (see online Supplementary figure S1).

In total, 76 workers were included in the study, of which 58 worked in the production areas and 18 in offices (non-exposed controls). Sampling was 
performed during 1 week in May and 1 week in August 2013 (at similar climate conditions) during all work shifts. Each worker was sampled during one shift, and the length of the shifts ranged from 5 to 13 hours. Sixty-five workers had been working the day before sampling. Five office workers had been on weekend leave before sampling. For six production workers, we lack information on whether they worked the day before sampling or not. In addition, we gathered information about work tasks performed on the study day, use of gloves and use of respiratory protection.

The study was performed in accordance with the Declaration of Helsinki. Participants provided written informed consent before they were included. At the end of the study, participants received their personal results and were given opportunity to ask questions.

\section{Sample collection}

Skin wipe samples were collected at two time points to verify the skin exposure: before the start of the shift, when workers had not changed into their work wear, and at the end of the work shift. In addition, we performed personal 8-hour air sampling and workers collected spot urine samples during 24 hours following the start of shift. For a detailed description of the sampling procedures and methods for analysis, please see our previous publication. ${ }^{10}$

All plastic appliances used in this study were acid cleaned in $10 \%$ nitric acid $\left(\mathrm{HNO}_{3}\right)$ and rinsed four times with deionised water $(16.7 \mathrm{M} \Omega / \mathrm{cm})$. All $\mathrm{HNO}_{3}$ was diluted from $65 \% \mathrm{HNO}_{3}$ (EMSURE ISO, Merck KGaA, Darmstadt, Germany) in deionised water, unless otherwise specified.

\section{Skin wipe sampling}

Co skin exposure was assessed with acid wipe sampling. ${ }^{25} \mathrm{~A}$ $2 \mathrm{~cm}^{2}$ skin surface on the volar aspect of the non-dominant index finger was wiped with three consecutive paper wipes moistened with $1 \% \mathrm{HNO}_{3}$. Wipes were pooled in a test tube and extracted in $1 \% \mathrm{HNO}_{3}$, before chemical analysis of wipe extracts.

\section{Air sampling}

Personal respiratory exposure to Co was monitored using a $25 \mathrm{~mm}$ filter cassette (Institute of Occupational Medicine inhalable fraction sampler, SKC Ltd, Dorset, UK) mounted in the breathing zone of the worker at flow rate $2.0 \mathrm{~L} / \mathrm{min}$, according to EN 481. ${ }^{112627}$ Air sampling was performed in 30 workers, selected to represent different exposure groups in the production area. We had access to company data on routine air monitoring showing no respiratory exposure to Co in the offices; hence, no air samples were collected for this group.

\section{Urine sampling}

Midstream spot urine samples of each void (up to $250 \mathrm{~mL}$ ) were collected by all workers during 24 hours from start of the shift. Each worker received bottles $(250 \mathrm{~mL}$, PE-HD, Emballator Mellerud Plast, Sweden) to collect each void separately. All urine samples were stored in a fridge on arrival in the lab. Specific gravity (SG) was measured using a refractometer (Euromex RD 712, Arnhem, the Netherlands) prior to freezing. Mean SG of the urine samples was used to correct for dilution variations in urine samples for the purpose of statistical analyses, ${ }^{28}$ according to

$$
\mathrm{C}_{\text {sample }}\left(\frac{\mathrm{SG}_{\text {pop }}-1}{\mathrm{SG}_{\mathrm{sample}}-1}\right)
$$

where $\mathrm{C}_{\text {sample }}$ is the concentration of Co in the urine sample, $\mathrm{SG}_{\text {pop }}$ is the mean SG of our study population (1.019 in May, 1.016 in August) and $S_{\text {sample }}$ is the $S G$ of the individual urine sample.

\section{Chemical analysis}

Samples were diluted for chemical analysis as previously described. ${ }^{10}$ Indium $(1 \mu \mathrm{g} / \mathrm{L})$ and rhodium $(5 \mu \mathrm{g} / \mathrm{L})$ were added as internal standards for acid wipe and urine samples, respectively. Inductively coupled plasma mass spectrometry (Thermo Fisher Scientific iCAP Q, Waltham, Massachusetts, USA) analysis in kinetic energy discrimination mode was used to analyse the intensity of ${ }^{59} \mathrm{Co},{ }^{115} \mathrm{In}$ and ${ }^{103} \mathrm{Rh}$ in diluted acid wipe extracts and urine samples. A six point calibration curve $(0,0.1,1,10$, $50,100 \mu \mathrm{g} / \mathrm{L}$ for acid wipe samples and $0,0.1,1,5,10,50 \mu \mathrm{g} / \mathrm{L}$ for urine samples) was made, using matrix-matched calibration standards prepared from dilution of a Co stock solution (996 $\pm 5 \mu \mathrm{g} / \mathrm{mL}$; Lot: F2-CO02044, Spectrascan, Teknolab AS, Norway) in $1 \% \mathrm{HNO}_{3}$ (analysis grade) for acid wipe extracts and in a diluted urine matrix for urine analysis. ${ }^{10}$

Limit of detection (LOD) for Co (three times the SD of the method blanks) ranged between $0.015 \mu \mathrm{g} / \mathrm{L}$ and $0.027 \mu \mathrm{g} / \mathrm{L}$ for acid wipe sample analysis and between 0.041 and $0.098 \mu \mathrm{g} / \mathrm{L}$ for urine sample analysis (LOD uncorrected for SG). For quality control purposes, Seronorm Trace Elements L-1 (LOT. 1403080) and L-2 (LOT. 1403081) (SERO AS, Billingstad, Norway) were used as reference material for urine analysis (see online Supplementary table S1).

Collected air samples were analysed by an International Organisation for Standardisation certified laboratory at Örebro University Hospital. The method for air filter preparation before analysis has been described elsewhere. ${ }^{10}$ LOD of the filter analysis was $0.007 \mu \mathrm{g} / \mathrm{L}$ for Co. STAMI filters (A4-0089 and A4-0116, National Institute of Occupational Health, Oslo, Norway) were used as reference material for quality control.

\section{Statistical analysis}

All four variables contained outliers and measures below the LOD. Median and range were therefore used to describe Co skin exposure before shift $\left(\mathrm{S}_{\mathrm{B}}-\mathrm{Co}\right)$, at end of shift $\left(\mathrm{S}_{\mathrm{E}}-\mathrm{Co}\right)$, in air (A-Co) and in urine (U-Co).

We evaluated associations between A-Co and either $\mathrm{S}_{\mathrm{B}}$-Co or $S_{E}$-Co with the Spearman's rank correlation coefficient. Differences in exposure across different groups were verified with the Wilcoxon rank-sum test.

We used log-transformed data for further statistical analysis, because distribution of all four variables was right skewed. Quantile regression was used to verify differences in log-transformed U-Co across groups. Furthermore, we performed quantile regression to evaluate the association between the dependent variable U-Co and the independent exposure variables. Quantile regression is similar to linear regression. ${ }^{29}{ }^{30}$ The main difference is that the former estimates any quantile of interest (eg, median, quartiles) of the outcome variable, while the latter estimates its mean. The quantile regression method permitted inclusion of all the available values, without having to impute measures below the LOD, and it was robust to the outlying values and marked skewness of the outcome variable. All logarithms were to base 2, because this facilitated interpretation of the observed ratio being the factor by which the dependent variable ( $\mathrm{U}-\mathrm{Co})$ is multiplied following a doubling of the covariate(s) $\left(\mathrm{S}_{\mathrm{B}}-\mathrm{Co}, \mathrm{S}_{\mathrm{E}}-\mathrm{Co}\right.$ and/or A-Co) included in the model. 
Table 1 Descriptive characteristics of 76 workers at the hard metal industry

\begin{tabular}{|c|c|c|c|c|c|}
\hline & \multicolumn{4}{|c|}{ Exposure group } & \multirow[b]{2}{*}{ Total } \\
\hline & Control & Raw material & Sintered material & Final product & \\
\hline Participating workers (n) & 18 & 24 & 16 & 18 & 76 \\
\hline Gender (m/f) & $10 / 8$ & $19 / 5$ & $7 / 9$ & $17 / 1$ & $53 / 23$ \\
\hline Age (mean (range)) & $45(24-61)$ & $42(21-65)$ & $46(24-60)$ & $44(28-60)$ & $44(21-65)$ \\
\hline Years employed (mean (range)) & $15.2(1-39)$ & $14.9(1-43)$ & $18.3(2-37)$ & $15.3(1.5-34)$ & $15.8(1-43)$ \\
\hline
\end{tabular}

We estimated three univariable regression models (1, 2 and 3) and two bivariable models (4 and 5). In model 1.1 and 1.2, the logarithm of $\mathrm{S}_{\mathrm{B}}$-Co was the only covariate, whereas in model 2.1 and 2.2 the only covariate was logarithm of $\mathrm{S}_{\mathrm{E}}$-Co. In model 3, logarithm of A-Co was the only covariate. In model 4, both the logarithm of $\mathrm{S}_{\mathrm{B}}$-Co and A-Co were included as covariates, and model 5 included the logarithm of $\mathrm{S}_{\mathrm{E}}$-Co and A-Co as covariates. In model 1.2 and 2.2, workers with high A-Co were excluded, thereby keeping the influence of air exposure on U-Co in these models as low as possible.

Departures from linearity on the log-scale were tested by introducing splines. The 95\% CIs are reported along with the point estimates. Because the measures were taken repeatedly on the same individuals, we estimated the SEs of the regression coefficient with 500 design-matrix bootstrap samples. All the analyses were performed in Stata V.14.

\section{RESULTS}

Workers were divided into four exposure groups (see online Supplementary table S2), and descriptive characteristics are presented in table 1 .

\section{Co on skin}

Skin exposures of Co before $\left(\mathrm{S}_{\mathrm{B}}-\mathrm{Co}\right)$ and at end of shift $\left(\mathrm{S}_{\mathrm{E}^{-}}\right.$ $\mathrm{Co})$ for the four groups are shown in table 2. The Wilcoxon rank-sum test was performed to evaluate if skin exposures $(\mu \mathrm{g} /$ $\mathrm{cm}^{2}$ ) were different between the groups at both time points for sampling (table 2).

Analysis showed that working with raw material resulted in a significantly higher median $\mathrm{S}_{\mathrm{B}}$-Co $\left(0.096 \mu \mathrm{g} / \mathrm{cm}^{2} ; \mathrm{p}<0.001\right)$ compared with all other groups. Median $\mathrm{S}_{\mathrm{B}}$-Co in sintered material, final product and control groups did not differ from each other $\left(0.013,0.014\right.$ and $0.012 \mu \mathrm{g} / \mathrm{cm}^{2}$, respectively).

Median $\mathrm{S}_{\mathrm{E}}$-Co was significantly lower in the control group compared with all other groups $\left(0.012 \mu \mathrm{g} / \mathrm{cm}^{2} ; \mathrm{p} \leq 0.001\right)$. The raw material group had significantly higher median $\mathrm{S}_{\mathrm{E}}$-Co than all other groups $\left(0.86 \mu \mathrm{g} / \mathrm{cm}^{2} ; \mathrm{p}<0.001\right)$. Differences in median $\mathrm{S}_{\mathrm{E}}$-Co between the groups working with sintered

Table 2 Median (range) doses of cobalt (Co) on skin $\left(\mu \mathrm{g} / \mathrm{cm}^{2}\right)$ for 76 workers in the hard metal industry

\begin{tabular}{lll}
\hline Exposure group & $\mathrm{S}_{\mathrm{B}}-\mathrm{Co}\left(\mu \mathrm{gg} / \mathrm{cm}^{2}\right)^{*}$ & $\mathrm{~S}_{\mathrm{E}}-\mathrm{Co}\left(\mu \mathrm{g} / \mathrm{cm}^{2}\right)^{*}$ \\
\hline Control $(\mathrm{n}=18)$ & $0.012(0.0024-0.086)$ & $0.012(0.00059-0.43) \dagger$ \\
Raw material $(\mathrm{n}=24)$ & $0.096(0.0090-0.76) \ddagger$ & $0.86(0.065-135) \ddagger$ \\
Sintered material $(\mathrm{n}=16)$ & $0.013(0.0030-0.035)$ & $0.046(0.015-0.99)$ \\
Final product $(\mathrm{n}=18)$ & $0.014(0.0036-0.038)$ & $0.12(0.0091-2.9)$
\end{tabular}

${ }^{*} \mathrm{C} 0$ on skin before start of shift $\left(\mathrm{S}_{\mathrm{B}}-\mathrm{Co}\right)$ and at end of shift $\left(\mathrm{S}_{\mathrm{E}}-\mathrm{Co}\right)$.

tMedian significantly lower $(p \leq 0.001)$ than that in all other groups, using Wilcoxon rank-sum test.

¥Median significantly higher $(p<0.001)$ than that in all other groups, using Wilcoxon rank-sum test. material $\left(0.046 \mu \mathrm{g} / \mathrm{cm}^{2}\right)$ and the final product $\left(0.12 \mu \mathrm{g} / \mathrm{cm}^{2}\right)$ were not statistically significant.

\section{Co in air}

Thirty air samples were collected, of which 13 belonged to the raw material, nine to the final product and eight to the sintered material groups. Two air samples of raw material workers were excluded from statistical analysis, since the workers wore respiratory protective equipment. Air samples from the breathing zone did therefore not represent their exposure. Working with raw materials gave rise to statistically significantly higher A-Co (median $5.6 \mu \mathrm{g} / \mathrm{m}^{3}$; $\mathrm{p}<0.001$ ) compared with sintered materials (median $0.13 \mu \mathrm{g} / \mathrm{m}^{3}$ ) and final product (median $0.14 \mu \mathrm{g} / \mathrm{m}^{3}$ ), tested with the Wilcoxon rank-sum test (table 3 ).

\section{Co in urine}

In total, 563 urine samples were collected, and on average seven (range 4-11) samples per person (table 4). Overall U-Co in samples above LOD ranged between 0.038 and $31 \mu \mathrm{g} / \mathrm{L}$. The only group with statistically significantly higher U-Co was raw material (median 1.8, range $0.13-31 \mu \mathrm{g} / \mathrm{L} ; \mathrm{p}<0.001$ ), tested with design-matrix bootstrapped quantile regression (table 4). No difference could be found between the other three groups.

\section{Correlation between S-Co and A-Co}

Spearman's rank correlation showed that A-Co correlated well with $\mathrm{S}_{\mathrm{E}}-\mathrm{Co}\left(\mathrm{r}_{\mathrm{s}}=0.801 ; \mathrm{p}<0.001\right)$ and to a lower degree with $\mathrm{S}_{\mathrm{B}}-\operatorname{Co}\left(\mathrm{r}_{\mathrm{s}}=0.448 ; \mathrm{p}<0.001\right)$.

\section{Quantile regression}

Using quantile regression, we could not find a significant change over time in U-Co related to exposure during the 24-hour period (online Supplementary figure S2).

In model 1.1, we used 76 individual pairs of $S_{B}-C o$ and U-Co to evaluate the effect of $\mathrm{S}_{\mathrm{B}}$-Co on $\mathrm{U}$-Co with quantile regression. There was a significant association, with an observed ratio of 1.70 (95\% CI 1.51 to $1.91, \mathrm{p}<0.001$ ) (figure $1 \mathrm{~B}$ and online Supplementary table S3). In model 1.2 , the effect of $S_{B}$-Co on

Table 3 Cobalt $(\mathrm{Co})$ concentration in air $\left(\mu \mathrm{g} \mathrm{Co} / \mathrm{m}^{3}\right)$ during full shift measurements (average $410 \mathrm{~min}$ ) in hard metal industry

\begin{tabular}{lcll}
\hline Exposure group & $\mathbf{n}$ & Median & Range \\
\hline Raw material & $11^{*}$ & $5.6 \dagger$ & $0.82-24 \ddagger$ \\
Sintered material & 8 & 0.13 & $0.012-0.55$ \\
Final product & 9 & 0.14 & $0.026-0.45$ \\
\hline
\end{tabular}

*Two air samples were excluded from the result and further statistical analysis because workers used respiratory protection.

tMedian significantly higher than median in other groups $(p<0.001)$ using Wilcoxon rank-sum test.

‡Two samples were above the Swedish Occupational Exposure Limit Value, $20 \mu \mathrm{g}$ $\mathrm{Co} / \mathrm{m}^{3}$. 
Table 4 Co concentration in urine; uncorrected and corrected for SG in urine samples from 76 workers in the hard metal industry

\begin{tabular}{lcll}
\hline & & \multicolumn{2}{l}{ Co in urine $(\mu \mathrm{g} / \mathrm{L})$ : median (range) } \\
\cline { 3 - 4 } Exposure group & Number of samples above LOD $(\%)$ & Uncorrected & SG corrected \\
\hline Control $(\mathrm{n}=18)$ & $73(55.7)$ & $0.22(0.074-1.1)$ & $0.20(0.058-2.1)$ \\
Raw material $(\mathrm{n}=24)$ & $160(92.5)$ & $1.7(0.049-26)$ & $1.8(0.13-31)^{*}$ \\
Sintered material $(\mathrm{n}=16)$ & $83(66.9)$ & $0.24(0.057-5.5)$ & $0.21(0.063-4.4)$ \\
Final product $(\mathrm{n}=18)$ & $90(66.7)$ & $0.31(0.072-8.3)$ & $0.32(0.040-7.2)$ \\
\hline
\end{tabular}

${ }^{*}$ Median significantly higher than the other groups, $p<0.001$, using design-matrix bootstrapped quantile regression.

Co, cobalt; LOD, limit of detection; SG, specific gravity.

U-Co was evaluated again, however, now excluding all raw material workers (52 individual pairs). The observed ratio was 1.33 (95\% CI 1.04 to $1.70, \mathrm{p}=0.021$ ) (online Supplementary table S3).

Using $\mathrm{S}_{\mathrm{E}}$-Co in model 2.1 with all 76 individual pairs, the observed ratio was 1.32 (95\% CI 1.17 to $1.49, \mathrm{p}<0.001)$ (figure 1C and online Supplementary table S3), whereas excluding all raw material workers in model 2.2, the observed ratio was 1.17 (95\% CI 1.06 to $1.30, \mathrm{p}=0.002)$ (online Supplementary table S3).

In model 3, we evaluated the effect of A-Co on the workers' U-Co. The 46 pairs that were used in this model included 28 A-Co samples monitored in this study (table 3 ) and an imputed A-Co value for the 18 workers in the control group $(0.010 \mu \mathrm{g} /$ $\left.\mathrm{m}^{3}\right)$. This value was assigned based on comparison with cobalt concentrations measured in air samples of the production workers in our study. The value was lower than the lowest value of Co concentration measured in production areas $\left(0.012 \mu \mathrm{g} / \mathrm{m}^{3}\right)$ and equal to the 1/2000 of the Swedish OEL indicating negligible respiratory exposure. The observed ratio between A-Co and U-Co was 1.38 (95\% CI 1.25 to $1.54, \mathrm{p}<0.001$ ) (figure $1 \mathrm{~A}$ and online Supplementary table S3).

In model 4, we showed the effect of $\mathrm{S}_{B}$-Co and A-Co together on U-Co (46 individual pairs). The observed ratio for $\mathrm{S}_{\mathrm{B}}$-Co was 1.27 (95\% CI 0.94 to $1.71, \mathrm{p}=0.118$ ), whereas the ratio for A-Co was 1.31 (95\% CI 1.13 to 1.52 , p<0.001) (online Supplementary table S3). Model 5 showed the effect of $\mathrm{S}_{\mathrm{E}}$-Co and A-Co together on U-Co (46 individual pairs). This provided an observed ratio for $\mathrm{S}_{\mathrm{E}}$-Co that was 0.98 (95\% CI 0.84 to 1.14, $\mathrm{p}=0.784)$, whereas the ratio for A-Co was 1.42 (95\% CI 1.19 to $1.70, \mathrm{p}<0.001$ ) (online Supplementary table S3).

\section{DISCUSSION}

To our knowledge, this is the largest study conducted to analyse the association between Co skin and respiratory exposure and urinary Co. Our findings confirmed skin and respiratory exposure of hard metal workers to Co as determinants of urinary Co concentration over a wide range of skin exposures $\left(0.00059-135 \mu \mathrm{g} / \mathrm{cm}^{2}\right)$ and respiratory exposures $(0.012-24 \mu \mathrm{g} /$ $\mathrm{m}^{3}$ ). Conversely, we did not find a time-dependent fluctuation in urinary Co concentrations that was related to Co exposure on the study day.

A weakness of this study is that air samples were not collected for all workers, although the data was enough to elucidate the association between A-Co and U-Co. Considering that $\mathrm{S}_{\mathrm{B}}-\mathrm{Co}$ and $\mathrm{S}_{\mathrm{E}}$-Co were strongly correlated with A-Co, our study may have lacked sufficient statistical power when assessing the joint contribution of these exposures on U-Co in the quantile regression model. Nevertheless, when the contribution of skin exposure was analysed in only workers mainly exposed on skin, the association of $\mathrm{S}_{\mathrm{B}}$-Co and $\mathrm{S}_{\mathrm{E}}$-Co with U-Co was still significant, indicating that skin exposure should not be neglected in these occupational settings.

Interestingly, we observed a stronger association between $\mathrm{U}-\mathrm{Co}$ and $\mathrm{S}_{\mathrm{B}}$-Co than between $\mathrm{U}-\mathrm{Co}$ and $\mathrm{S}_{\mathrm{E}}-\mathrm{Co}$, irrespective of excluding raw material workers in the analysis. After the shift, the skin was normally cleaned; however, residues of the
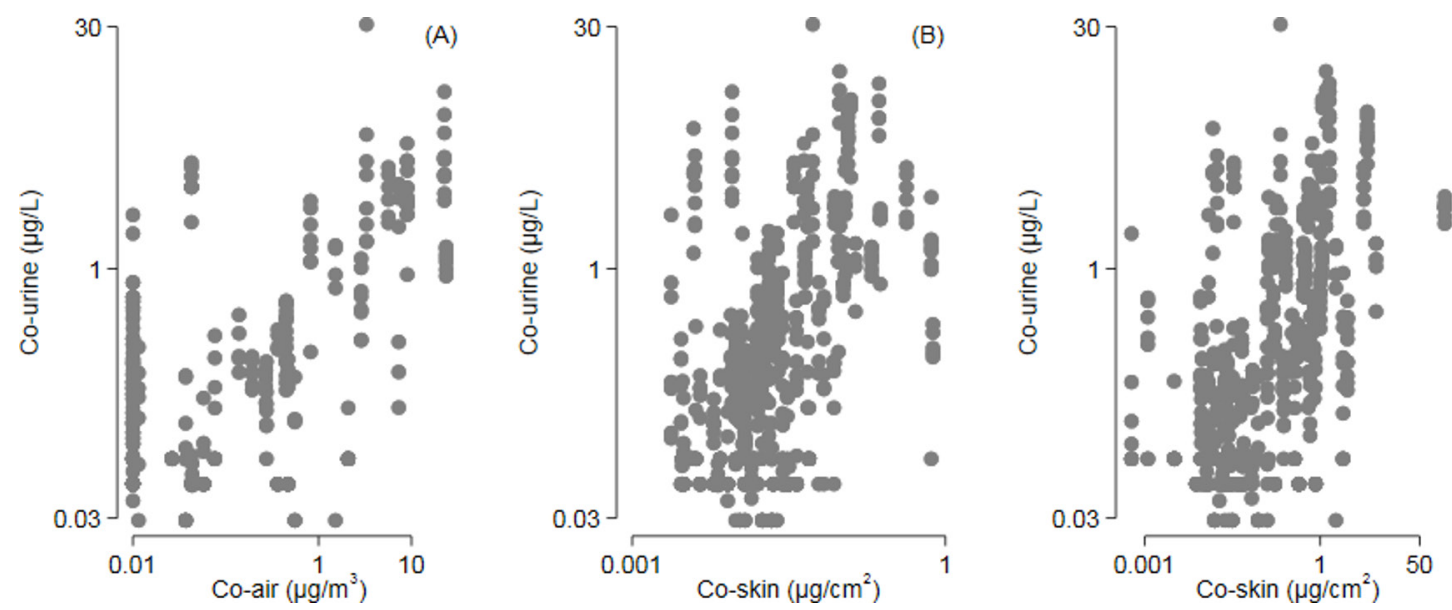

(C)

Figure 1 (A) Association between cobalt (Co) in inhalable dust $\left(\mathrm{A}-\mathrm{C}_{0} ; \mu \mathrm{g} / \mathrm{m}^{3}\right)$ and $\mathrm{Co}_{0}$ in urine $(\mathrm{U}-\mathrm{C} 0 ; \mu \mathrm{g} / \mathrm{L})$ for 46 workers at the hard metal industry in Sweden. Control group workers were assigned a value of $0.010 \mu \mathrm{g} / \mathrm{m}^{3}$ for statistical analysis. Two air samples were excluded from statistical analysis because the workers used respiratory protection. (B) Association between skin exposure before start of shift $\left(\mathrm{S}_{B}-\mathrm{Co}_{;} \mu \mathrm{g} / \mathrm{cm}^{2}\right)$ and $\mathrm{U}$-Co for 76 workers. (C) Association between skin exposure at end of shift $\left(\mathrm{S}_{\mathrm{E}}-\mathrm{C} 0 ; \mu \mathrm{g} / \mathrm{cm}^{2}\right)$ and U-Co for 76 workers. Concentrations below limit of detection were treated as $\mathrm{LOD} / \sqrt{2}$. All variables are on base 2 logarithmic scale. Note the different scales on the $x$-axes. 
skin exposure may remain, ${ }^{6} 3132$ thereby causing a continuous, low-dose exposure as reflected in the $S_{B}$-Co values. Since we had no information about whether and how long before the end of shift workers had washed their hands, this may have attenuated the results in the models using $\mathrm{S}_{\mathrm{E}}-\mathrm{Co}$.

Our study was performed during a regular work day without prior vacation which can be considered a strength, as the results are comparable to everyday working circumstances. We did not find any time-dependent fluctuation in urinary Co concentration related to Co exposure during the studied shift, which has also been observed by other researchers. ${ }^{33}$ Urinary excretion of Co after respiratory exposure may range from hours to weeks or years. ${ }^{2034}$ Furthermore, urinary excretion after Co skin exposure has only been studied twice in healthy volunteers, and excretion reached a maximum within 24 hours. ${ }^{56}$ Some researchers have proposed a spot urine sample at the end of shift at the end of a work week as the optimal sampling strategy for biological monitoring of Co. ${ }^{561921}$ However, recently published data revealed that exposure misclassification was likely if relying on a single spot urine sample. ${ }^{35}$ A strength of our study is that we used multiple spot urine samples, thereby reducing the risk of exposure misclassification.

Co deposited on skin can contribute to urinary Co levels via skin absorption, as indicated in in vitro studies using human skin $^{2324}$ and the above-mentioned reasoning regarding urinary excretion in human volunteers. ${ }^{5}{ }^{6}$ In addition, oral exposure may have contributed to Co in urine by hand-to-mouth activities which were not monitored in our study design. However, the employer required the workers to wash their hands before smoking or eating. The impact of this is difficult to evaluate since only 10 workers in our study were smokers. Linnainmaa and Kiilunen showed that smoking and intake of vitamin $B_{12}$ have small to no influence on urinary Co concentrations. ${ }^{6}$ This probably relates to the fact that faeces is the primary excretion route following oral administration. ${ }^{20}$

Our study was not designed to elucidate between oral exposure by hand-to-mouth activity or skin absorption, but only to assess the possible associations between skin exposures and urinary levels of Co to emphasis the importance of monitoring skin exposure.

Many studies have demonstrated the usefulness of Co in urine or blood as biomarkers of Co respiratory exposure. ${ }^{5} 615$ 17-19 2133 Urine $^{56}$ and blood ${ }^{15}$ have only been used as biomarker for skin exposure in a few studies. In this study, urinary Co was used as biomarker of both exposure routes. It is a non-invasive method, and Co levels are usually higher in urine compared with blood, which makes them easier to detect.

\section{CONCLUSIONS}

Urinary Co was demonstrated to be a suitable biomarker for multiple exposure routes for a wide exposure range. Considering the significant associations in our analysis, we can conclude that Co skin exposure can be used as an additional determinant of urinary Co concentrations. This should be taken into consideration when using urine as a biomarker of respiratory exposure-the approach of the global hard metal industry today. More studies are needed to determine if $\mathrm{Co}$ is absorbed through skin and thereby contributing to urinary Co concentrations or if other factors are also relevant.

Acknowledgements We thank Lennart Lundgren and Lizbet Skare for their help with sampling at the hard metal industry. Bernt Bergström and Carin Pettersson at Örebro University Hospital are acknowledged for chemical analysis of air samples. We acknowledge Professor Inger Odnevall Wallinder and Gunilla Herting at the
Division of Surface and Corrosion Science, Royal Institute of Technology (KTH) in Stockholm for performing preliminary sample analysis. We would also like to thank the hard-metal company and its employees for participating in the study.

Contributors $\mathrm{KM}, \mathrm{CL}$ and $\mathrm{AJ}$ applied for funding, ethical permission and designed the study. JK, KM and AJ prepared and performed the sampling and evaluated data. JK and KM performed the chemical analysis. JK, AJ and MB performed statistical analysis and interpreted the result and drafted the manuscript. All authors contributed to improving the manuscript and approved the final version.

Funding This study was financially supported by the Swedish Research Council for Health, Working Life and Welfare (Forte, research grants no 2012-1105 and 20091765).

Competing interests None declared.

Patient consent Not required.

Ethics approval The regional ethical review board in Stockholm (dnr 2012/180231/1).

Provenance and peer review Not commissioned; externally peer reviewed.

Open access This is an open access article distributed in accordance with the Creative Commons Attribution Non Commercial (CC BY-NC 4.0) license, which permits others to distribute, remix, adapt, build upon this work non-commercially, and license their derivative works on different terms, provided the original work is properly cited, appropriate credit is given, any changes made indicated, and the use is non-commercial. See: http://creativecommons.org/licenses/by-nc/4.0/.

\section{REFERENCES}

1 Lidén C. Cobalt. In: Rustemeyer T, Elsner P, John S, eds. Kanerva's occupational dermatology. Berlin, Heidelberg: Springer, 2012:505-10.

2 Lison D. Chapter 25 - cobalt. In: Nordberg GF, Fowler BA, Nordberg M, eds. Handbook on the toxicology of metals. 3rd edn. Burlington: Academic Press, 2007.

3 International Agency for Research on Cancer (IARC). Monographs on the evaluation of carcinogenic risks to humans. Volume 86: Cobalt in hard metals and cobalt sulfate, gallium arsenide, indium phosphide and vanadium pentoxide, Lyon, France. 2006. http://monographs.iarc.fr/ENG/Monographs/vol86/mono86.pdf (accessed Feb 2018).

4 Rystedt I, Fischer T. Relationship between nickel and cobalt sensitization in hard metal workers. Contact Dermatitis 1983;9:195-200.

5 Scansetti G, Botta GC, Spinelli P, et al. Absorption and excretion of cobalt in the hard metal industry. Sci Total Environ 1994;150:141-4.

6 Linnainmaa M, Kiilunen M. Urinary cobalt as a measure of exposure in the wet sharpening of hard metal and stellite blades. Int Arch Occup Environ Health 1997;69:193-200.

7 Lee JY, Yoo JM, Cho BK, et al. Contact dermatitis in Korean dental technicians. Contact Dermatitis 2001;45:13-16.

8 Uter W, Rühl R, Pfahlberg A, et al. Contact allergy in construction workers: results of a multifactorial analysis. Ann Occup Hyg 2004;48:21-7.

9 Shiao JS, Sheu HM, Chen CJ, et al. Prevalence and risk factors of occupational hand dermatoses in electronics workers. Toxicol Ind Health 2004;20:1-7.

10 Kettelarij J, Nilsson S, Midander K, et al. Snapshot of cobalt, chromium and nickel exposure in dental technicians. Contact Dermatitis 2016;75:370-6.

11 Kettelarii JA, Lidén C, Axén E, et al. Cobalt, nickel and chromium release from dental tools and alloys. Contact Dermatitis 2014;70:3-10.

12 Julander A, Lundgren L, Skare L, et al. Formal recycling of e-waste leads to increased exposure to toxic metals: an occupational exposure study from Sweden. Environ Int 2014;73:243-51

13 Stefaniak AB, Virji MA, Day GA. Characterization of exposures among cemented tungsten carbide workers. Part I: Size-fractionated exposures to airborne cobalt and tungsten particles. J Expo Sci Environ Epidemio/ 2009;19:475-91.

14 Julander A, Skare L, Mulder M, et al. Skin deposition of nickel, cobalt, and chromium in production of gas turbines and space propulsion components. Ann Occup Hyg 2010;54:340-50

15 Klasson M, Lindberg M, Bryngelsson IL, et al. Biological monitoring of dermal and air exposure to cobalt at a Swedish hard metal production plant: does dermal exposure contribute to uptake? Contact Dermatitis 2017;77:201-7.

16 Kettelarij J, Midander K, Lidén C, et al. Contamination of skin and surfaces by cobalt in the hard metal industry. Contact Dermatitis. In Press. 2018.

17 Mosconi G, Bacis M, Vitali MT, et al. Cobalt excretion in urine: results of a study on workers producing diamond grinding tools and on a control group. Sci Total Environ 1994;150:133-9.

18 Alexandersson R. Blood and urinary concentrations as estimators of cobalt exposure. Arch Environ Health 1988;43:299-303.

19 Lison D, Buchet JP, Swennen B, et al. Biological monitoring of workers exposed to cobalt metal, salt, oxides, and hard metal dust. Occup Environ Med 1994:51:447-50.

$20 \mathrm{Kim} \mathrm{JH}, \mathrm{Gibb} H J$, Howe PD. Cobalt and inorganic cobalt compounds. Geneva: World Health Organization, 2006

21 Scansetti G, Lamon S, Talarico $S$, et al. Urinary cobalt as a measure of exposure in the hard metal industry. Int Arch Occup Environ Health 1985;57:19-26. 
22 Martin A, Bois FY, Pierre F, et al. Occupational exposure to cobalt: a population toxicokinetic modeling approach validated by field results challenges the biological exposure index for urinary cobalt. J Occup Environ Hyg 2010;7:54-62.

23 Larese $\mathrm{F}$, Gianpietro A, Venier $\mathrm{M}$, et al. In vitro percutaneous absorption of metal compounds. Toxicol Lett 2007;170:49-56.

24 Larese Filon F, Maina G, Adami G, et al. In vitro percutaneous absorption of cobalt. Int Arch Occup Environ Health 2004;77:85-9.

25 Lidén C, Skare L, Lind B, et al. Assessment of skin exposure to nickel, chromium and cobalt by acid wipe sampling and ICP-MS. Contact Dermatitis 2006;54:233-8.

26 European Committee for Standardization (CEN). Workplace atmospheres - Size fraction definitions for measurement of airborne particles. EN 481: CEN, 1993.

27 International Organization for Standardization. ISO/FDIS 15202-1: workplace air - determination of metals and metalloids in airborne particulate matter by inductively coupled plasma atomic emission spectrometry. Part 1: Sampling. Geneva, Switzerland: ISO, 2012:1-20.

28 Suwazono Y, Akesson A, Alfvén T, et al. Creatinine versus specific gravity-adjusted urinary cadmium concentrations. Biomarkers 2005; 10:117-26.
29 Koenker R, Bassett G. Regression quantiles. Econometrica 1978;46:33-50.

30 Cade BS, Noon BR. A gentle introduction to quantile regression for ecologists. Front Ecol Environ 2003;1:412-20.

31 Sato M, Yano E. The association between lead contamination on the hand and blood lead concentration: a workplace application of the sodium sulphide (Na2S) test. Sci Total Environ 2006;363:107-13.

32 Lewinski NA, Berthet A, Maurizi L, et al. Effectiveness of hand washing on the removal of iron oxide nanoparticles from human skin ex vivo. J Occup Environ Hyg 2017:14:D115-19.

33 Princivalle A, lavicoli I, Cerpelloni M, et al. Biological monitoring of cobalt in hard metal factory workers. Int Arch Occup Environ Health 2017;90:243-54.

34 Simonsen LO, Harbak H, Bennekou P. Cobalt metabolism and toxicology - a brief update. Sci Total Environ 2012;432:210-5.

35 Wang $Y X$, Feng $W$, Zeng Q, et al. Variability of metal levels in spot, first morning, and 24-hour urine samples over a 3-month period in healthy adult Chinese men. Environ Health Perspect 2016;124:468-76. 